ERRATUM

\title{
Secretagogues govern GH secretory-burst waveform and mass in healthy eugonadal and short-term hypogonadal men
}

Johannes D Veldhuis and Daniel M Keenan ${ }^{1}$

Endocrine Research Unit, Clinical Translational Research Unit, Mayo Medical and Graduate Schools, Mayo Clinic, Rochester, Minnesota 55905, USA and

${ }^{1}$ Department of Statistics, University of Virginia, Charlottesville, Virginia 22904, USA

(Correspondence should be addressed to J D Veldhuis; Email: veldhuis.johannes@mayo.edu)

The authors and the journal apologize for an error in the above paper which appeared in 159 (5) 547-554. On page 553 the correct sentence should read 'The latter consideration would be consistent with the fact that E2 can repress expression of the pituitary SSTR5 gene in the rodent, and relieve inhibition of GH secretion by infused SS in the humans $(31,32)$ '.

European Journal of Endocrinology 159841 